\title{
Pricing levered warrants with dilution using observable variables *
}

\author{
Isabel Abínzano \\ Universidad Pública de Navarra \\ isabel.abinzano@unavarra.es
}

\author{
Javier F. Navas \\ Universidad Pablo de Olavide \\ jfernav@upo.es
}

This version: January 15, 2013

\begin{abstract}
We propose a valuation framework for pricing European call warrants on the issuer's own stock that allows for debt in the issuer firm. In contrast to other works which also price warrants with dilution issued by levered firms, ours uses only observable variables. Thus, we extend the models of both Crouhy and Galai (1994) and Ukhov (2004). We provide numerical examples to study some implementation issues and to compare the model with existing ones.
\end{abstract}

Journal of Economic Literature classification: C13, C63, G32.

Keywords: Corporate warrants, dilution, leverage, observable variables.

\footnotetext{
${ }^{*}$ We are grateful for valuable comments from David Abad, Julio Carmona, Ariadna Dumitrescu, Louis Ederington, Stewart Hodges, Belén Nieto, David Offenberg, Gonzalo Rubio, Eduardo Schwartz, Andrey Ukhov, Ashraf Zaman, seminar participants at a number of conferences and universities and an anonymous referee. We acknowledge the financial support of the Andalusian Regional Government (grants P08-SEJ-03917 and P09-SEJ-4467) and the Spanish Ministry of Economy and Competitiveness (grants ECO2012-35946-C02-01 and ECO2012-34268). Javier F. Navas also acknowledges the hospitality of Carlos III University and Purdue University, where part of this work was done. An earlier version of this work appeared as Working Paper No. 450 in the Working Paper Series of the Fundación de las Cajas de Ahorros (FUNCAS). The usual disclaimer applies.
} 


\section{Introduction}

Like European call options, European call warrants give the holder the right to purchase a specified amount of an asset at an agreed price, on a fixed date. There are two types of warrants: warrants on the company's own stock, also known as corporate or equity warrants, and warrants on other assets, usually called covered warrants or bank-issued options. In the former case, the exercise of the warrant in exchange for new shares results in a dilution of the firm's own stock. Black and Scholes (1973), Merton (1973), Galai and Schneller (1978), Noreen and Wolfson (1981), Galai (1989), and Lauterbach and Schultz (1990), among others, value warrants as call options on shares of the equity of the firm and take into account this dilution effect. However, there is no consensus in the literature regarding whether this dilution effect should or should not be taken into account when pricing the warrants. There are authors who value warrants as options on the firm's stock and claim that the dilution effect should be fully reflected in the stock price and, as a consequence, there is no need to correct for dilution; see, for example, Sidenius (1996), Handley (2002), and Bajo and Barbi (2010). The explanation for this opposing view is that the assumptions of the different models are not compatible. Equity-based models assume that the value of equity (that is, the value of the firm, since there is no debt) follows a lognormal process, while stock-based models assume that it is the stock price that follows the lognormal process. Both these things cannot be true at the same time. The assumption that the stock price follows a lognormal process is particularly difficult to justify when the firm has warrants outstanding (see Bajo and Barbi, 2010). Hence, it may be convenient to consider warrants as shares on the equity of the firm, in which case correction for dilution will be needed. This is consistent with the recent empirical findings of Chang and Liao (2010) and a recent study by Yagi and Sawaki (2010), where dilution effects are considered when pricing callable warrants. ${ }^{1}$

In the valuation formulas obtained by the equity-based models, firm market value and its volatility need to be known, which is not possible. Moreover, when there are warrants outstanding, firm value is itself a function of the warrant price. To

\footnotetext{
${ }^{1}$ Other empirical papers finding correction for dilution necessary are Schulz and Trautmann (1994) and Darsinos and Satchell (2002).
} 
overcome these problems, Schulz and Trautmann (1994) and Ukhov (2004) propose a warrant-pricing procedure based on the price and volatility of the underlying stock.

The above studies value warrants issued by companies financed by shares and warrants. The majority of firms, however, are also debt financed. To reflect this fact, Crouhy and Galai (1994) develop a pricing model for the valuation of warrants issued by levered companies. Later, Koziol (2006) extends the analysis of Crouhy and Galai to explore optimal warrant exercise strategies in the case of American warrants.

Both Crouhy-Galai's formula and its extension in Koziol (2006) depend on the value of a firm with the same investment policy as the one issuing the warrant but financed entirely with shares of stock. Therefore, these pricing models again present the drawback of dependence on unobservable variables. In this paper, we devise a model for the valuation of warrants issued by levered companies, where only the values of observable variables need to be known. Unlike Crouhy and Galai (1994) and Koziol (2006), we place no restrictions on debt maturity.

The remainder of the paper is organized as follows. Section 2 briefly reviews the valuation of warrants with dilution. Section 3 presents our suggested approach to the valuation of warrants, which depends on the relationship between debt maturity and warrant maturity. Section 4 examines the implementation of the model through some numerical examples. Finally, section 5 contains the conclusions of our study.

\section{Review of existing models}

\subsection{Classical warrant valuation with dilution}

A recurring issue in the corporate warrant pricing literature is the fact that the value of a warrant is a function of the issuer's firm value, which in turn includes the warrant value and is unobservable. Many authors ${ }^{2}$ explicitly acknowledge this problem and value warrants using an expression typically known as the "correct warrant valuation formula" (see Veld, 2003). We next introduce a unifying notation and briefly present the model.

\footnotetext{
${ }^{2}$ Such as Galai and Schneller (1978), Ingersoll (1987), Galai (1989), Schulz and Trautmann (1989, 1994), and Crouhy and Galai (1991).
} 
Let there be a firm financed by $N$ shares of stock and $M$ European call warrants. Each warrant gives the holder the right to $k$ shares $^{3}$ at time $t=T$ in exchange for the payment of an amount $X$. Let $V_{t}$ be the asset value of the firm at time $t$, let $S_{t}$ and $\sigma_{S}$ be the price and volatility of the underlying stock, respectively, and let $w_{t}$ be the warrant price at time $t$.

If the $M$ warrants are exercised at $t=T$, the firm receives an amount of money $M X$ and issues $M k$ new shares of stock. Thus, immediately before the exercise of the warrants, each warrant must be worth $\max \left\{\frac{k}{N+k M}\left(V_{T}+M X\right)-X, 0\right\}$. Warrant holders will exercise their warrants only when this value is non-negative, that is, when $k V_{T} \geq N X$. Thus, the warrant price at date of exercise can be expressed as follows

$$
w_{T}=\frac{1}{N+k M} \max \left(k V_{T}-N X, 0\right)
$$

Supposing that the assumptions of Black and Scholes (1973) hold for $V_{t}$, the following expression for the warrant price follows

$$
w_{t}=\frac{1}{N+k M}\left[k V_{t} \Phi\left(d_{1}\right)-e^{-r(T-t)} N X \Phi\left(d_{2}\right)\right]
$$

with

$$
\begin{aligned}
& d_{1}=\frac{\ln \left(k V_{t} / N X\right)+\left(r+\sigma_{V}^{2} / 2\right)(T-t)}{\sigma_{V} \sqrt{T-t}} \\
& d_{2}=d_{1}-\sigma_{V} \sqrt{T-t}
\end{aligned}
$$

where $\Phi(\cdot)$ is the distribution function of a Normal random variable and $\sigma_{V}$ is the return volatility of $V_{t}$.

Clearly, the classical warrant pricing formula depends on $V_{t}$ and $\sigma_{V}$, which are unobservable variables.

\subsection{Schulz and Trautmann (1994) and Ukhov (2004) model}

To obtain a warrant-pricing formula where only the values of observable variables are needed, Schulz and Trautmann (1994) relate $V_{t}$ and $\sigma_{V}$ to the underlying share

\footnotetext{
${ }^{3} k$ is usually referred to as the warrant ratio.
} 
price, $S_{t}$, and its return volatility, ${ }^{4} \sigma_{S}$, as follows

$$
\sigma_{S}=\sigma_{V} \Delta_{S} \frac{V_{t}}{S_{t}}
$$

where $\Delta_{S}=\partial S_{t} / \partial V_{t}$. Given that $V_{t}=N S_{t}+M w_{t}$, the following expression is satisfied

$$
N \Delta_{S}+M \Delta_{w}=\Delta_{V}=1
$$

where $\Delta_{w}=\partial w\left(V_{t} ; \cdot\right) / \partial V_{t}$. Furthermore, using (2) we have that

$$
\Delta_{w}=\frac{k}{N+k M} \Phi\left(d_{1}\right)
$$

Substituting the above into (6), the analytic expression for $\Delta_{S}$ is obtained

$$
\Delta_{S}=\frac{1-M \Delta_{w}}{N}=\frac{N+k M-k M \Phi\left(d_{1}\right)}{N(N+k M)}
$$

Finally, substituting the expression (8) into (5), we obtain the relationship between the unobservable variables, $V_{t}$ and $\sigma_{V}$, and the observable variables $S_{t}$ and $\sigma_{S}$.

Using this relationship, the warrant price is obtained with the following algorithm (as explained by Ukhov, 2004):

1. Solve (numerically) the following system of non-linear equations for $\left(V_{t}^{*}, \sigma_{V}^{*}\right)$

$$
\left\{\begin{array}{l}
N S_{t}=V_{t}-\frac{M}{N+k M}\left[k V_{t} \Phi\left(d_{1}\right)-e^{-r(T-t)} N X \Phi\left(d_{2}\right)\right] \\
\sigma_{S}=\frac{V_{t}}{S_{t}} \Delta_{S} \sigma_{V}
\end{array}\right.
$$

with

$$
\Delta_{S}=\frac{N+k M-k M \Phi\left(d_{1}\right)}{N(N+k M)}
$$

and where

$$
\begin{aligned}
& d_{1}=\frac{\ln \left(k V_{t} / N X\right)+\left(r+\sigma_{V}^{2} / 2\right)(T-t)}{\sigma_{V} \sqrt{T-t}} \\
& d_{2}=d_{1}-\sigma_{V} \sqrt{T-t}
\end{aligned}
$$

\footnotetext{
${ }^{4}$ Obviously, despite stock returns being an observable variable, the volatility of stock returns is non-observable; thus, we use the term "observable variables" as in Ukhov (2004).
} 
2. The warrant price, $w_{t}$, is computed as

$$
w_{t}=\frac{V_{t}^{*}-N S_{t}}{M}
$$

A proof that a solution $\left(V_{t}^{*}, \sigma_{V}^{*}\right)$ of the system of non-linear equations (9)-(12) exists is contained in Ukhov (2004). Note that the formula provided by Schulz and Trautmann (1994) and Ukhov (2004) does not require knowledge of the firm's value nor of its volatility.

\subsection{Crouhy and Galai (1994) model}

Despite the advantage of using only the values of observable variables, the above model has the limitation of assuming that the issuer of the warrant is a pure-equity firm.

Crouhy and Galai (1994) develop a more realistic model that allows for debt, although it is not based on observable variables. Specifically, they consider a firm financed by $N$ shares of stock, $M$ European call warrants and debt $D$. The debt consists of a zero-coupon bond with face value $F$ and maturity $T_{D}$. For every warrant held, the holder has the right to purchase $k$ shares of stock at $T$, in exchange for the payment of an amount $X$.

Following Ingersoll (1987) and other authors, Crouhy and Galai assume that the proceeds from exercising the warrants are reinvested in the company. They also assume no economies of scale and a stationary return distribution for one unit of investment, independent of firm size. The remaining assumptions of Crouhy and Galai (1994) are that the risk-free interest rate, $r$, is known and constant, and that there are perfect market conditions.

Crouhy and Galai study only the case in which the warrant issuer is financed with a zero-coupon bond with a maturity longer than that of the warrants, that is, $T<T_{D}$. To derive their formula, they consider a firm with the same investment policy as the firm issuing the warrant, but financed entirely by common stock. Under the assumption of perfect capital markets, Modigliani and Miller (1958) show that the value of any firm is independent of its capital structure. ${ }^{5}$ Hence, the initial value of the reference firm is the same as that of the levered firm. At $t=0$, the reference

\footnotetext{
${ }^{5}$ This is the well-known Proposition I of MM.
} 
firm issues $N^{\prime}$ shares of stock at a price $V_{0}^{\prime} / N^{\prime}=S_{0}^{\prime}$, while the warrant-issuing firm issues $N$ shares of stock, $M$ warrants and a zero-coupon bond with maturity $T_{D}>T$. Hence, we can write for $0 \leq t<T$ that

$$
V_{t}=N S_{t}+M w_{t}+D_{t}, \text { with } V_{t}=V_{t}^{\prime}
$$

where $S_{t}, w_{t}$ and $D_{t}$ are, respectively, the values of a share, a warrant and the debt of the levered firm at time $t$. Thus, the warrant value at any time prior to the exercise date is given by the following expression

$$
w_{t}=\frac{V_{t}^{\prime}-N S_{t}-D_{t}}{M}, \text { with } t<T
$$

If the warrants are exercised at $t=T$, an amount $M X$ is reinvested in the company, thus, the value of the levered company as of the date of exercise may differ from the reference firm value. If the warrants have not been exercised at $t=T$, the value of the levered company at $t=T_{D}$ will be equal to the reference asset value, $V_{T_{D}}^{\prime}$.

The exercise of the warrants at $t=T$ depends on whether the value of the shares received by the warrant-holders is greater than the exercise price. Although the traditional analysis ${ }^{6}$ considers that warrants should be exercised if the value of the shares immediately prior to the exercise date is greater than $X$, Crouhy and Galai (1994) show that this condition may lead to erroneous decisions and argue that warrants should be exercised if the value of the shares of stock is greater than $X$ immediately after expiration.

We can write the post-expiration value of a share of stock at $t=T, S_{T}$, as follows

$$
S_{T}= \begin{cases}\frac{V_{T}^{\prime}-D_{T}^{N W}}{N} \equiv S_{T}^{N W} & \text { if warrants are not exercised at } t=T \\ \frac{V_{T}^{\prime}+M X-D_{T}^{W}}{N+k M} \equiv S_{T}^{W} & \text { if warrants are exercised at } t=T\end{cases}
$$

where $V_{T}^{\prime}$ is the reference firm value at $t=T$, and $D_{T}^{W}, D_{T}^{N W}, S_{T}^{W}$ and $S_{T}^{N W}$ denote the debt value and the price of a share of stock in the company immediately after $T$, when the warrants are exercised and when the warrants are not exercised, respectively. Given that $S_{T}^{W}$ is an increasing function of $V_{T}^{\prime}$, there exists a unique value of $V_{T}^{\prime}, \bar{V}_{T}^{\prime}$, for which the warrant-holders are indifferent as to whether to exercise

\footnotetext{
${ }^{6}$ See for example Ingersoll (1987), Schulz and Trautmann (1994) and Ukhov (2004).
} 
their warrants or let them expire, that is, $k S_{T}^{W}\left(\bar{V}_{T}^{\prime}\right) \equiv X$. Thus, for reference asset values above (below) $\bar{V}_{T}^{\prime}$, the warrants will (will not) be exercised at $t=T$.

Alternatively, we can write the above expression as follows

$$
S_{T}= \begin{cases}\frac{c\left(V_{T}^{\prime}, F, T_{D}-T\right)}{N} \equiv S_{T}^{N W} & \text { if } V_{T}^{\prime} \leq \bar{V}_{T}^{\prime} \\ \frac{c\left(V_{T}^{\prime}+M X, F, T_{D}-T\right)}{N+k M} \equiv S_{T}^{W} & \text { if } V_{T}^{\prime}>\bar{V}_{T}^{\prime}\end{cases}
$$

where $c(x, K, T)$ denotes the value of a European call option on $x$, with strike $K$ and time to maturity $T$, and where $\bar{V}_{T}^{\prime}$ is the reference firm value at which the warrants may be exercised. Under the assumptions that the reference asset value $V_{t}^{\prime}$ follows a lognormal process and that there are no arbitrage opportunities, there exists a risk-neutral probability measure under which $e^{-r t} V_{t}^{\prime}$ is a martingale, therefore we can write

$$
d V_{t}^{\prime}=r V_{t}^{\prime} d t+\sigma_{V^{\prime}} V_{t}^{\prime} d Z_{t}^{\prime}
$$

where $\sigma_{V^{\prime}}$ is the return volatility of $V_{t}^{\prime}$, and $Z_{t}^{\prime}$ is a standard Brownian motion. A consequence of this assumption is that for any time $t$, with $t<T$, we can value the firm's shares discounting their expected value at $T$ at the risk-free discount rate, $r$

$$
S_{t}=e^{-r(T-t)} E^{*}\left[\frac{c\left(V_{T}^{\prime}, F, T_{D}-T\right)}{N} I_{V_{T}^{\prime} \leq \bar{V}_{T}^{\prime}}+\frac{c\left(V_{T}^{\prime}+M X, F, T_{D}-T\right)}{N+k M} I_{V_{T}^{\prime}>\bar{V}_{T}^{\prime}} \mid \mathcal{F}_{t}\right]
$$

where $E^{*}$ denotes the expected value under the risk-free probability measure, $\mathcal{F}_{t}$ is the available information set at time $t$, and $I_{\text {[condition] }}$ is an indicator that takes a value of 1 when the condition is satisfied and 0 otherwise.

Furthermore, we know that the solution of the process given by (18) is

$$
V_{T}^{\prime}=V_{t}^{\prime} \exp \left(\left(r-1 / 2 \sigma_{V^{\prime}}^{2}\right)(T-t)+\sigma_{V^{\prime}}\left(Z_{T}^{\prime}-Z_{t}^{\prime}\right)\right)
$$

Thus, $V_{T}^{\prime}$ follows a lognormal distribution, that is, $\left[\ln V_{T}^{\prime}\right] \mid V_{t}^{\prime} \sim \Phi\left(\ln V_{t}^{\prime}+(r-\right.$ $\left.\left.0.5 \sigma_{V^{\prime}}^{2}\right)(T-t), \sigma_{V^{\prime}}^{2}(T-t)\right)$.

Using the properties of the lognormal distribution, Crouhy and Galai finally compute the stock price as follows

$$
\begin{aligned}
S_{t} & =\frac{e^{-r(T-t)}}{\sqrt{2 \pi(T-t)}}\left(\int_{-\infty}^{\bar{y}} \frac{c\left(V_{T}^{\prime}, F, T_{D}-T\right)}{N} e^{-\frac{y^{2}}{2}} d y\right. \\
& \left.+\int_{\bar{y}}^{\infty} \frac{c\left(V_{T}^{\prime}+M X, F, T_{D}-T\right)}{N+k M} e^{-\frac{y^{2}}{2}} d y\right)
\end{aligned}
$$


where $y\left(V_{T}^{\prime}\right)=\frac{\ln \frac{V_{T}^{\prime}}{V_{t}^{\prime}}+\left(r-\frac{1}{2} \sigma_{V^{\prime}}^{2}\right)(T-t)}{\sigma_{V^{\prime}} \sqrt{T-t}}$.

Analogously, the value of debt at time $t$, with $t<T$, is given by

$$
\begin{aligned}
D_{t} & =F e^{-r\left(T_{D}-t\right)}-\frac{e^{-r(T-t)}}{\sqrt{2 \pi(T-t)}}\left(\int_{-\infty}^{\bar{y}} p\left(V_{T}^{\prime}, F, T_{D}-T\right) e^{-\frac{y^{2}}{2}} d y\right. \\
& \left.+\int_{\bar{y}}^{\infty} p\left(V_{T}^{\prime}+M X, F, T_{D}-T\right) e^{-\frac{y^{2}}{2}} d y\right)
\end{aligned}
$$

The expressions for $S_{t}$ and $D_{t}$ are substituted into equation (15) to obtain the warrant price $w_{t}$, as a function of the reference asset value $V_{t}^{\prime}$, and its volatility $\sigma_{V^{\prime}}$.

\section{New warrant-pricing models}

In this section, we allow for debt in the firm and we develop a model based on the issuer's stock price and its volatility. Depending on the exercise date, we value the warrants in three cases: a) when they have the same maturity as the debt $\left(T=T_{D}\right)$, b) when they expire before the debt $\left(T<T_{D}\right)$, and c) when they expire after the debt $\left(T>T_{D}\right)$. Thus, we extend the works of Ukhov (2004) and Crouhy and Galai (1994), and we deal with the case of long-term warrants for the first time in the literature (to the best of our knowledge).

\subsection{Warrants with the same maturity as debt}

Like Crouhy and Galai, we suppose a firm financed by $N$ shares of stock, $M$ European call warrants and debt $D$. The debt is a pure discount bond with face value $F$ and maturity $T_{D}$. Every warrant offers the right to purchase $k$ shares of stock at time $T=T_{D}$, with exercise price $X$. The remaining assumptions of Crouhy and Galai (1994) hold.

The owner of the warrant has the right to pay $X$ at $T$ and receive $k$ shares of stock with individual value $\frac{1}{N+k M}\left(E_{T}+M X\right)$, where $E_{T}$ is the value of equity at $T$, just after the maturity of debt and immediately prior the exercise of the warrants. Thus, we can express the value of the warrant at $t=T$ as

$$
w_{T}=\max \left(0, k \lambda\left(E_{T}+M X\right)-X\right)
$$


where $\lambda=\frac{1}{N+k M}$. Furthermore, we know that $E_{T}=\max \left(V_{T}-F, 0\right)$, because if the value of the company at $T$ is greater than the face value of debt, $F$, debtholders get $F$ while shareholders get $V_{T}-F$, and in case of default, the debtholders receive what is left of the company, $V_{T}$, while the shareholders get 0 . Thus, we can write

$$
w_{T}=\max \left(0, \max \left(k \lambda\left(V_{T}-F+M X\right)-X,-\lambda N X\right)\right)
$$

Additionally, since the values of $\lambda, N$ and $X$ are non-negative, we can express $w_{T}$ as follows

$$
w_{T}=\lambda \max \left(0, k V_{T}-k F-N X\right)
$$

Thus, at time $t=T$ the holder of a warrant receives the same payoff as the owner of $\lambda$ European call options on $k V_{t}$, with strike $k F+N X$ and maturity $T$. Under the Black-Scholes-Merton assumptions, the value of the warrant is given by

$$
w\left(V_{t}, \sigma_{V}, X\right)=\lambda\left[k V_{t} \Phi\left(f_{1}\right)-e^{-r(T-t)}(k F+N X) \Phi\left(f_{2}\right)\right]
$$

with

$$
\begin{aligned}
& f_{1}=\frac{\ln \left(\frac{k V_{t}}{k F+N X}\right)+\left(r+\frac{1}{2} \sigma_{V}^{2}\right)(T-t)}{\sigma_{V} \sqrt{T-t}} \\
& f_{2}=f_{1}-\sigma_{V} \sqrt{T-t}
\end{aligned}
$$

Hence, we have expressed the value of the warrant as a function of the firm value, $V_{t}$, and its volatility, $\sigma_{V}$. Since these variables cannot be observed, on the basis of Ukhov (2004), we look for a relationship linking $V_{t}$ and $\sigma_{V}$ with $S_{t}$ and $\sigma_{S}$. As we have seen before, we can use the following expression

$$
\sigma_{S}=\frac{V_{t}}{S_{t}} \Delta_{S} \sigma_{V}
$$

where $\Delta_{S}=\frac{\partial S_{t}}{\partial V_{t}}$. To compute $\Delta_{S}$ in the presence of debt we now see that $V_{t}=$ $N S_{t}+M w_{t}+D_{t}$, so we have that

$$
\Delta_{V}=1=N \Delta_{S}+M \Delta_{w}+\Delta_{D}
$$

Using (26) we obtain the following

$$
\Delta_{w}=\frac{\partial w_{t}}{\partial V_{t}}=k \lambda \Phi\left(f_{1}\right)
$$


On the other hand, to obtain the expression for $\Delta_{D}$ we must first determine the expression for $D_{t}$. We know that the payoff received by debtholders at maturity can be written as: $D_{T}=\min \left(F, V_{T}\right)=F-\max \left(0, F-V_{T}\right)$. Hence, $D_{t}$ can be expressed as

$$
D_{t}=F e^{-r(T-t)}-p\left(V_{t}, F, T-t\right)
$$

where $p(x, K, T)$ is the value of a European put option on $x$ with strike price $K$ and time to maturity $T$. Thus, $\Delta_{D}$ is given by this expression

$$
\Delta_{D}=\frac{\partial D_{t}}{\partial V_{t}}=1-\Phi\left(h_{1}\right)
$$

where

$$
h_{1}=\frac{\ln \frac{V_{t}}{F}+\left(r+\frac{1}{2} \sigma_{V}^{2}\right)(T-t)}{\sigma_{V} \sqrt{T-t}}
$$

As a consequence, we have established the link between the unobservable and the observable variables, relating $V_{t}$ to $S_{t}, \sigma_{s}$, and $\sigma_{V}$.

We can summarize our warrant-pricing algorithm as follows

1. Solve (numerically) the following system of nonlinear equations for $\left(V_{t}^{*}, \sigma^{*}\right)$

$$
\left\{\begin{array}{l}
N S_{t}= \\
V_{t} \Phi\left(h_{1}\right)-e^{-r(T-t)} F \Phi\left(h_{2}\right)-M \lambda\left[k V_{t} \Phi\left(f_{1}\right)-e^{-r(T-t)}(k F+N X) \Phi\left(f_{2}\right)\right] \\
\sigma_{S}=\frac{V_{t}}{S_{t}} \Delta_{S} \sigma_{V}
\end{array}\right.
$$

with

$$
\begin{aligned}
\Delta_{S} & =\frac{\Phi\left(h_{1}\right)-\frac{k M}{N+k M} \Phi\left(f_{1}\right)}{N} \\
f_{1} & =\frac{\ln \left(\frac{k V_{t}}{k F+N X}\right)+\left(r+\frac{1}{2} \sigma_{V}^{2}\right)(T-t)}{\sigma_{V} \sqrt{T-t}} \\
f_{2} & =f_{1}-\sigma_{V} \sqrt{T-t} \\
h_{1} & =\frac{\ln \left(\frac{V_{t}}{F}\right)+\left(r+\frac{1}{2} \sigma_{V}^{2}\right)(T-t)}{\sigma \sqrt{T-t}} \\
h_{2} & =h_{1}-\sigma_{V} \sqrt{T-t}
\end{aligned}
$$

and where $\lambda=\frac{1}{N+k M}$. 
2. Finally, the warrant price at $t$ is obtained as

$$
w_{t}=\lambda\left[k V_{t}^{*} \Phi\left(f_{1}\right)-e^{-r(T-t)}(k F+N X) \Phi\left(f_{2}\right)\right]
$$

It is easy to show that when the firm has no debt, this procedure coincides with Ukhov's. Additionally, when the effect of dilution is negligible, that is, $\frac{M}{N} \rightarrow 0$, the pricing expression collapses to the Black-Scholes-Merton formula.

\subsection{Warrants with shorter maturity than debt}

We now suppose that the warrant issuer is financed with a zero-coupon bond with longer maturity than the warrants, that is, $T<T_{D}$.

As in the previous case, we first use the Crouhy and Galai (1994) model to obtain an expression for warrants' value that depends on unobservable variables (the reference firm value and its volatility, $V_{t}^{\prime}$ and $\sigma_{V^{\prime}}$ ). We then follow Ukhov (2004) and establish a relationship between these variables and the firm's stock price, $S_{t}$, and its return volatility, $\sigma_{S}$.

To relate these variables, we use equation (21), which relates the variables $V_{t}^{\prime}$ and $\sigma_{V^{\prime}}$ with the stock price, $S_{t}$, and the following expression to relate $V_{t}^{\prime}, \sigma_{V^{\prime}}$ and $S_{t}$ with $\sigma_{S}$ given by

$$
\sigma_{S}=\sigma_{V^{\prime}} \frac{\partial S_{t}}{\partial V_{t}^{\prime}} \frac{V_{t}^{\prime}}{S_{t}}
$$

where $S_{t}$ is given by $(21)$.

Thus, the warrant pricing algorithm now appears as follows

1. Solve (numerically) the following system of non-linear equations for $\left(V_{t}^{*}, \sigma_{V^{\prime}}^{*}\right)$

$$
\left\{\begin{aligned}
S_{t} & =\frac{e^{-r(T-t)}}{\sqrt{2 \pi(T-t)}}\left(\int_{-\infty}^{\bar{y}} \frac{c\left(V_{T}^{\prime}, F, T_{D}-T\right)}{N} e^{-\frac{y^{2}}{2}} d y+\int_{\bar{y}}^{\infty} \frac{c\left(V_{T}^{\prime}+M X, F, T_{D}-T\right)}{N+k M} e^{-\frac{y^{2}}{2}} d y\right) \\
\sigma_{S} & =\sigma_{V^{\prime}} \frac{\partial S_{t}}{\partial V_{t}^{\prime}} \frac{V_{t}^{\prime}}{S_{t}}
\end{aligned}\right.
$$

where $c(x, K, T)$ denotes the value of a European call option on $x$, with strike $K$ and time to maturity $T$, whereas $\bar{V}_{T}^{\prime}$ denotes the value of $V_{T}^{\prime}$ that satisfies $k \frac{c\left(V_{T}^{\prime}+M X, F, T_{D}-T\right)}{N+k M}=X, \bar{y}=y\left(\bar{V}_{T}^{\prime}\right)$, and $y\left(V_{T}^{\prime}\right)=\frac{\ln \frac{V_{T}^{\prime}}{V_{t}^{\prime}}+\left(r-\frac{1}{2} \sigma_{V^{\prime}}^{2}\right)(T-t)}{\sigma_{V^{\prime}} \sqrt{T-t}}$. Recall that $V_{T}^{\prime}=V_{t}^{\prime} \exp \left(\left(r-1 / 2 \sigma_{V^{\prime}}^{2}\right)(T-t)+\sigma_{V^{\prime}}\left(Z_{T}^{\prime}-Z_{t}^{\prime}\right)\right)$. 
2. The warrant price at time $t$, with $t<T$, is obtained as

$$
w_{t}=\frac{V_{t}^{\prime *}-N S_{t}-D_{t}}{M}
$$

with $D_{t}$ given by

$$
\begin{aligned}
D_{t} & =F e^{-r\left(T_{D}-t\right)}-\frac{e^{-r(T-t)}}{\sqrt{2 \pi(T-t)}}\left(\int_{-\infty}^{\bar{y}} p\left(V_{T}^{*}, F, T_{D}-T\right) e^{-\frac{y^{2}}{2}} d y\right. \\
& \left.+\int_{\bar{y}}^{\infty} p\left(V_{T}^{* *}+M X, F, T_{D}-T\right) e^{-\frac{y^{2}}{2}} d y\right)
\end{aligned}
$$

where $p(x, K, T)$ is the value of a European put option on $x$, with strike price $K$ and time to maturity $T$.

It is worth mentioning that we have no closed-form expression for $\frac{\partial S_{t}}{\partial V_{t}^{\prime}}$, so we need to compute it numerically.

\subsection{Warrants with longer maturity than debt}

Let us now consider the case of long-term warrants, with $T>T_{D}$. Although this situation is unlikely in reality, we study it for completeness.

If there has been no default at time $T_{D}$, at $t=T$ the owner of a warrant can pay $X$ and receive $k$ shares of stock with individual value $\frac{1}{N+k M}\left(E_{T}+M X\right)$, where $E_{T}$ is the value of equity immediately prior to the exercise of the warrants. Thus, as in equation (23), we can write

$$
w_{T}=\max \left(0, k \lambda\left(E_{T}+M X\right)-X\right)
$$

Since at time $T$ there is no debt, and assuming no previous default, we have that $E_{T}=V_{T}^{\prime}-F$, so this expression can be written as

$$
w_{T}=\lambda \max \left(0, k V_{T}^{\prime}-k F-N X\right)
$$

Thus, we can write the value of a warrant at $t=T$ as

$$
w_{T}= \begin{cases}0 & \text { if } V_{T_{D}}^{\prime}<F\left(\text { default at } T_{D}\right) \\ \lambda \max \left(0, k V_{T}^{\prime}-k F-N X\right) & \text { if } V_{T_{D}}^{\prime} \geq F\left(\text { no default at } T_{D}\right)\end{cases}
$$


Consequently, we have that at $t=T_{D}$, just after debt maturity, the warrant value is

$$
w_{T_{D}}= \begin{cases}0 & \text { if } V_{T_{D}}^{\prime}<F \\ \lambda c\left(k V_{T_{D}}^{\prime}, k F+N X, T-T_{D}\right) & \text { if } V_{T_{D}}^{\prime} \geq F\end{cases}
$$

where $c(x, K, T)$ denotes the value of a European call option on $x$, with strike $K$ and time to maturity $T$.

Assuming, as before, that the value of the reference firm follows a lognormal process and that there are no arbitrage opportunities, then relative asset prices are martingales, so we can write

$$
\begin{aligned}
w_{t} & =e^{-r\left(T_{D}-t\right)} E^{*}\left[w_{T_{D}}\right]= \\
& =e^{-r\left(T_{D}-t\right)} E^{*}\left[\lambda c\left(k V_{T_{D}}^{\prime}, k F+N X, T-T_{D}\right) I_{V_{T_{D}}^{\prime} \geq F} \mid \mathcal{F}_{t}\right] \\
& =\frac{e^{-r\left(T_{D}-t\right)}}{\sqrt{2 \pi\left(T_{D}-t\right)}} \int_{\bar{y}}^{\infty} \lambda c\left(k V_{T_{D}}^{\prime}, k F+N X, T-T_{D}\right) e^{-\frac{y^{2}}{2}} d y
\end{aligned}
$$

where $y(\cdot)$ and $\sigma_{V^{\prime}}$ have been defined before, and where $\bar{y}=\frac{\ln \frac{F}{V_{t}^{\prime}}+\left(r-\frac{1}{2} \sigma_{V^{\prime}}^{2}\right)\left(T_{D}-t\right)}{\sigma_{V^{\prime}} \sqrt{T_{D}-t}}$.

Up to this point, we have a relationship between the value of the warrant and the unobservable variables $V_{t}^{\prime 7}$ and $\sigma_{V^{\prime}}$. The next step is to provide a relationship between these variables and the price of the underlying stock and its return volatility. To this end, we use the fact that, before debt maturity, shareholders and warrantholders jointly own a European call option on the value of the company, with strike equal to the face value of debt, and with exercise date $T_{D}$; that is, $N S_{t}+M w_{t}=c\left(V_{t}^{\prime}, F, T_{D}-t\right)$, where $w_{t}$ is given by (50). Additionally, we use the expression $\sigma_{S}=\sigma_{V^{\prime}} \Delta_{S} V_{t}^{\prime} / S_{t}$.

Finally, the warrant-pricing algorithm now takes the following form

1. Solve (numerically) the following system of non-linear equations for $\left(V_{t}^{\prime *}, \sigma_{V^{\prime}}^{*}\right)$ :

$$
\left\{\begin{array}{l}
N S_{t}+M \frac{e^{-r\left(T_{D}-t\right)}}{\sqrt{2 \pi\left(T_{D}-t\right)}} \int_{\bar{y}}^{\infty} \lambda c\left(V_{T_{D}}^{\prime}, F, T-T_{D}\right) e^{-\frac{y^{2}}{2}} d y=c\left(V_{t}^{\prime}, F, T_{D}-t\right) \\
\sigma_{S}=\sigma_{V^{\prime}} \frac{\partial S_{t}}{\partial V_{t}^{\prime}} \frac{V_{t}^{\prime}}{S_{t}}
\end{array}\right.
$$

where $c(x, K, T)$ denotes the value of a European call option on $x$, with strike $K$ and time to maturity $T$, and with $\lambda=\frac{1}{N+k M}, y\left(V_{T_{D}}^{\prime}\right)=\frac{\ln \frac{V_{T_{D}}^{\prime}}{V_{t}^{\prime}}+\left(r-\frac{1}{2} \sigma_{V^{\prime}}^{2}\right)\left(T_{D}-t\right)}{\sigma_{V^{\prime}} \sqrt{T_{D}-t}}$

\footnotetext{
${ }^{7}$ Note that we can easily express $V_{t}^{\prime}$ in terms of $V_{T}^{\prime}$.
} 
and $\bar{y}=\frac{\ln \frac{F}{V_{t}^{\prime}}+\left(r-\frac{1}{2} \sigma_{V^{\prime}}^{2}\right)\left(T_{D}-t\right)}{\sigma_{V^{\prime}} \sqrt{T_{D}-t}}$. Recall that $V_{T}^{\prime}=V_{t}^{\prime} \exp \left(\left(r-1 / 2 \sigma_{V^{\prime}}^{2}\right)(T-t)+\right.$ $\left.\sigma_{V^{\prime}}\left(Z_{T}^{\prime}-Z_{t}^{\prime}\right)\right)$

2. The warrant price at time $t$, with $t<T_{D}$, is obtained as

$$
w_{t}\left(V_{t}^{\prime *}, \sigma_{V^{\prime}}^{*}\right)=\frac{e^{-r\left(T_{D}-t\right)}}{\sqrt{2 \pi\left(T_{D}-t\right)}}\left(\int_{-\infty}^{\bar{y}} \lambda c\left(V_{T_{D}}^{\prime}, F, T-T_{D}\right) e^{-\frac{y^{2}}{2}} d y .\right.
$$

\section{Numerical examples}

In this section we provide some examples to illustrate the behavior of warrant-pricing models. Following Ukhov, we consider a firm with $N=100$ shares outstanding. The current stock price and the volatility of stock returns are given. We contemplate three levels of stock prices, $S,\left(75,100\right.$, and 110) and two of volatilities, $\sigma_{S},(25 \%$ and $40 \%)$. The firm is also financed with debt and warrants. The debt consists of zerocoupon risky bonds with face value $F=1,000$ and maturity $T_{D}$. To study different degrees of dilution due to the issuance of warrants, we assume that the number of warrants, $M$, takes the values 10, 50, and 100. Every warrant offers the right to buy one share of the stock (i.e. $k=1$ ) after paying the exercise price $X=100$ at maturity (time $T$ ). The value of the firm at time $t$ is given by $N S_{t}+M W_{t}+D_{t}$, where $W_{t}$ and $D_{t}$ denote the market values of warrants and debt. The instantaneous risk-free interest rate is $r=0.0488$.

We construct three tables based on the relationship between the maturities of warrants and debt. Each has six panels, which reflect two volatility levels and three degrees of dilution. The structure of the tables is based on Ukhov's paper. Warrant prices are obtained in seven different ways (five models in each table). The first column in each table shows the underlying stock price, $S$. The second uses the BlackScholes-Merton (BSM) formula to calculate warrant values when the warrants are priced as simple stock options, $w_{B S M}$. The third column reports the prices obtained with the classical warrant-pricing model (CWM), which assumes that the firm has no debt. Since most firms have debt, this assumption is too strong. This model is based on the firm value, $V$, and its volatility, $\sigma_{V}$, as given by expression (2). The CWM assumes that the value of the firm is equal to the value of equity. In our calculations, we approximate the value of equity of the firm by $\widetilde{E}=N S+M w_{B S M}$. 
We also approximate the volatility of firm returns, $\sigma_{V}$, by the volatility of stock returns, $\sigma_{S}$. The fourth column (STU) provides warrant prices obtained with the model developed by Schulz and Trautman (1994) and Uhkov (2004) by solving the system of equations (9). This model is consistent with the current stock price and its volatility but still ignores the debt of the firm. In the fifth column, we value the warrants with the classical valuation model again this time assuming that the firm value is estimated as $V=\widetilde{E}+F e^{-r T_{D}}$, where $F e^{-r T_{D}}$ is the value of debt under the assumption of risk-free debt. Thus, we assume that the investor ignores debt when pricing the warrants but is able to obtain a good approximation to the market value of the firm. Notice that this valuation will be wrong. As before, the volatility of firm returns is approximated by $\sigma_{S}$. In column 6 of the tables, we incorporate debt correctly into models that are still based on the firm value and its volatility. In columns 7-9 we value the warrants taking debt into account and using only observable variables. We report the total firm value (column 7 ), the volatility of firm returns (column 8) and the warrant price (column 9) that are consistent with market data (the stock price and its volatility). Finally, in columns 10-12 we change the face value of the debt to $F=10,000$ and keep the remaining variables as before. We again indicate the firm value, the volatility of firm returns and the warrant price. We must interpret the last of these values with care because, contrary to what might appear at first sight, it does not allow us to study the effect of leverage on warrant prices. Analysis of this effect requires a different setting, where firm value and its volatility are invariant with leverage and where the volatility of stock returns and the number of shares change with the amount of debt. Such an analysis is well beyond the scope of this paper.

We start by comparing the models with no debt (BSM, CWM, and STU in columns 2-4) across the tables, and find the differences to be small. For example, in Table I, Panel B1 (high volatility, low dilution), we have that the prices of ATM warrants are 32.5992, 31.7675, and 32.5671, respectively. We also see that warrant prices are affected by dilution: ${ }^{8}$ CWM prices decrease clearly with dilution, while STU prices decrease more slowly and may even increase slightly (for OTM warrants of short maturity and low volatility, as shown in Table II). CWM prices are always

\footnotetext{
${ }^{8}$ Except for the BSM model, where dilution is not considered.
} 
lower than BSM prices, especially for high dilution. CWM prices are also always lower than STU prices, particularly for high dilution. Moreover, the difference in prices is greater for high dilution, reflecting the fact that, with dilution, CWM prices fall faster than STU prices. Finally, comparing STU and BSM prices, we have that, in general, the former are lower than the latter. However, there are cases where the opposite is true (ATM or OTM warrants with low volatility and low dilution).

As explained before, we introduce debt into the models for the first time in column 5, model CWMD. The assumption is that the investor is able to correctly assess the market value of the firm but is unable to develop a pricing model incorporating debt. He, therefore, uses the classical warrant pricing model to value the warrants. Obviously, firm value now increases and drives up warrant prices. The effect is stronger for low dilution and low volatility. For the case mentioned in the previous paragraph, ATM warrants in Panel B1 of Table I, the warrant value is 37.6269 .

We next take debt properly into account in the remaining columns (6-12) of the tables. We distinguish three cases, based on three different debt maturity periods. In Table I we study the valuation of warrants when they mature at the same time as the debt. We assume that time to maturity is 3 years $\left(T=T_{D}=3\right)$. Warrant values are computed with the models mentioned before (BSM, CWM, STU, and CWMD), with the classical model properly extended with debt -we call it LWM1V (column 6), which stands for our first "levered warrant model" based on the firm value (see expression (26)), and with this levered warrant model based on the stock price, LWM1SA (column 9), as given by expressions (35) - (41). Note that we also give the firm values and the corresponding volatilities that satisfy this system of equations (columns 7 and 8). In columns 10-12 we value the warrants as in columns 7-9 but assuming that the initial amount of debt in the firm has a face value of $F=10,000$. We refer to this calculation as LWM1SB.

Comparing columns 6 and 9 in Table I, we see that LWM1V values can be greater or smaller than LWM1SA ones, but the differences are not very great. In Panel A2, for example, we have that the value of an OTM warrant is 30.0140 for LWM1V and 31.3195 for LWM1SA. In the latter case, the firm value and firm value volatility consistent with market data are $13,429.78$ and $28.30 \%$, respectively. As mentioned 
before, in columns 10-12 we consider the case where the initial amount of debt is higher $(F=10,000)$. The firm value consistent with this situation is $21,248.19$ (very different from before), while the value of the warrant is similar: 32.2393 .

Comparison of LWM1SA with the other levered warrant pricing models in Table I yields a series of differences. We obtain generally lower ITM warrant prices and higher ATM and OTM warrant prices (especially for low volatility) with the LWM1SA than with the BSM model; we always obtain higher prices with LWM1SA than with CWM. In comparison with the STU model, we see that when the model includes debt with the same maturity as the warrant, the values of ITM warrants show a small reduction, while the values of ATM and OTM warrants show a small increase. The results hold for different levels of dilution and volatility.

Finally, warrant prices clearly decrease with dilution for LWM1V but can increase slightly for LWM1SA (ATM and OTM warrants, low volatility and high debt levels).

Thus, we can conclude from Table I that when the warrants have the same maturity as the debt: 1) warrant prices decrease with dilution, and 2) when debt is incorporated into the model, the values of ITM warrants decrease slightly and the values of ATM and OTM warrants increase.

In Table II, we value warrants when their maturity is smaller than the maturity of the debt $\left(T=1, T_{D}=3\right)$. Since the maturity period of the warrants is shorter, warrant prices will obviously be smaller than in Table I. As before, seven valuations are studied: BSM, CWM, STU, CWMD, the Crouhy and Galai (1994) model (CG), and our second valuation model (LWM2SA and LWM2SB). It is important to point out that, to the best of our knowledge, this is a novel implementation of the CG model in the literature. Although Crouhy and Galai (1994) calculate warrant prices with their model, as given by expression (15), they do so only near the exercise date of the warrants and not at the current time $t$. When implementing the CG model, we take $V_{t}^{\prime}=\widetilde{E}_{t}+F e^{-r T_{D}}$ as initial value of the reference firm, and $\sigma_{V^{\prime}}=\sigma_{S}$ as the volatility of firm returns. $>$ From these, we find the reference asset value, $\bar{V}_{T}^{\prime}$, above which the warrants are exercised. That is, we find the value of $V_{T}^{\prime}$ that satisfies $\frac{c\left(V_{T}^{\prime}+100 M, 1000,2\right)}{N+M}=100$, where $c(\cdot)$ is given by the Black and Scholes (1973) option pricing formula. Using the value of $\bar{V}_{T}^{\prime}$ thus obtained, we simulate by Monte Carlo the value of $V_{t}^{\prime}$ from $t=0$ to $t=T$. In each run, the firm value is determined 
as a function of whether the value of $V_{T}^{\prime}$ given by the simulation is above or below $\bar{V}_{T}^{\prime}$, for which we use the expression of $S_{t}$ given by (17). If the warrants are not exercised, the debt value at $t=T$ is $D_{T}^{N W}=V_{T}^{\prime}-N S_{T}^{N W}$ and the warrant value is $w_{T}=0$, whereas if the warrants are exercised, we calculate the debt value as $D_{T}^{W}=V_{T}^{\prime}+M X-(N+k M) S_{T}^{W}$ and the warrant value as $w_{T}=k S_{T}^{W}-X$. Finally, after running 1.000.000 simulations, we obtain the values of $S_{t}, D_{t}$ and $w_{t}$. Thus, in Panel A (low volatility), we see that the CG model overprices LWM2SA when dilution is low. LWM2SA prices are computed solving the system of equations (43)-(45). For the remaining cases, the CG model tends to underprice our model. Note that this did not happen in Table I. The price differences are larger for OTM warrants and high dilution.

We also note in Table II that BSM overprices LWM2SA for OTM warrants and underprices it for other warrants (as in Table I). The price differences increase with dilution, and can be as great as 32.46\% (ITM warrants and high dilution, 1.9052 versus 1.4382$)$. We finally observe that warrant prices decrease with dilution in the CG model and can increase in our model (for ATM and ITM warrants). We always obtain higher prices with LWM2SA than with CWM, as shown in Table I Finally, comparing STU and LWM2SA, we see that when we incorporate debt with longer maturity than the maturity of the warrants into the model, the prices of ITM warrants decrease slightly and the prices of ATM and OTM warrants show a small increase. This result holds for different levels of dilution ( as in Table I). With respect to LWM2SB, we note that for higher debt levels, warrant prices increase in general, except for ITM and ATM warrants with low and medium dilution, where the opposite is true. For the high volatility case (Panel B), warrant prices increase substantially, and the differences between models are smaller. Now, warrant prices always decrease with dilution for both LWM2SA and CG.

Thus, we can conclude from Table II that when the maturity of the warrants is shorter than that of the debt: 1) warrant prices can increase with dilution and 2) when debt is taken into account, warrant prices decrease slightly for ITM warrants and increase for ATM and OTM warrants (as in Table I).

Finally, in Table III, we value long-term warrants, which expire after the debt $\left(T=3, T_{D}=1\right)$. This situation, as already mentioned, will be quite uncommon. In 
the table, we value the warrants with: 1) BSM, 2) CWM, 3) STU, 4) CWMD, 5) our third valuation model based on firm value (LWM3V, as given by expression (50)), 6) our third valuation model based on the stock price (LWM3SA, which solves the system (51)-(52)), and 7) our third valuation model based on the stock price with a different amount of debt (LWM3SB). Since the maturity of the warrants is the same as in Table I, the models not incorporating debt produce the same warrant values as in Table I (that is, columns 2, 3, and 4 of tables 1 and 3 are identical). Since the maturity of the debt is shorter than in Table I, both debt and firm values are now higher, which helps to explain why the models incorporating debt produce higher warrant prices in Table III than in Table I. The data in Panel A of Table III (low volatility case) show that LWM3V warrant prices decrease with dilution and are always greater than CWM prices. Also, the LWM3V model overprices the LWM3SA model when dilution is low and underprices it when dilution is medium or high. The underpricing is greater for ITM warrants and high dilution. In LWM3SA, warrant prices can increase slightly with dilution (for ATM and OTM warrants and low dilution levels).

We also see from Table III that the BSM model slightly underprices LWM3SA in almost all cases. The price differences decrease somewhat with dilution. Finally, warrant prices clearly decline with dilution in LWM3V and tend to decrease in LWM3SA. Relative to the STU model, we see that, if dilution is not low, the incorporation of debt with shorter maturity than that of the warrants decrease warrant prices; if dilution is low, the warrant prices increase with the debt (for any given moneyness). With respect to the LWM3SB model, we can say that with high debt levels, we obtain greater warrant prices for any degree of moneyness, dilution, or volatility. The results for Panel 2 (high volatility) are similar. Warrant prices are higher and, generally, decrease with dilution.

Thus, we can conclude from Table III that when the maturity of the warrants is larger than that of the debt: 1) warrant prices decrease with dilution and 2) when debt is incorporated into the model, warrant prices decrease for medium or high dilution and increase for low dilution.

To summarize our results, although many different comparisons between models are possible, we have focused on comparing models incorporating debt. To this end, 
we have implemented our three algorithms, an extension of the classical warrant pricing model, the Crouhy and Galai (1994) model, and versions of our models based on firm value. We have also used the BSM formula, the classical warrant pricing model and the Schulz-Trautman-Ukhov model as references. We find that, although in many cases theoretical warrant prices are similar, substantial differences between models are also possible. As an example, investors using the BSM model could overprice warrants by more than $30 \%$ relative to our model (see Table II). We also find that models based on firm value are not consistent, in general, with the observed market data. This happens because when we compute the stock price and the volatility of stock returns implicit in the valuation process, we obtain values that are different from the initial ones. Thus, the incorporation of debt and the use of observable variables appear to be important when pricing corporate warrants.

\section{Conclusions}

We present a warrant valuation model that extends previous ones. Our model prices European call warrants on the issuer's own stock taking debt into account. It is based on the issuer's stock price and the volatility of stock returns, thus avoiding the need to estimate firm value and its volatility, and allowing consistency with market data.

We consider three cases depending on the exercise date of the warrants: warrants with the same maturity as the debt, warrants expiring before the debt, and warrants with longer maturity than the debt.

To derive a valuation formula for each situation, we first draw on the works of Ingersoll (1987) and Crouhy and Galai (1994) to express the value of the warrant as a function of unobservable variables. We then relate these variables to the underlying stock price and its return volatility.

To study the implementation of our valuation framework, we provide some numerical examples. We study warrant prices given by the models for different dilution levels, underlying stock prices, and stock return volatilities.

We contribute to the literature in various ways. First, we extend the work of Ukhov (2004) allowing the issuing firm to have debt. Second, we extend the model of Crouhy and Galai (1994) to the case of observable variables. We note, as an 
aside, our novel implementation of the actual Crouhy and Galai model, where the maturity of the warrants is shorter than that of the debt. When warrants mature at the same time as the debt, the Crouhy and Galai (1994) cannot be used. Thus, our third contribution is to extend the classical warrant valuation model to include debt with the same maturity as the warrants. This is one of the models used in our comparisons. Finally, the fourth contribution of the paper is the valuation of long-term levered warrants. We provide pricing formulas for this case based on the stock price as well as on the firm value.

The overall conclusion of the paper is that allowing for debt in the issuing firm seems to be important for warrant pricing purposes, and that it is possible to do so with a model that is consistent with market data. 


\section{References}

Bajo, E. and Barbi, M., 2010. The risk-shifting effect and the value of a warrant, Quantitative Finance, 10, 10, 1203-1213.

Black, F. and Scholes, M., 1973. The pricing of options and corporate liabilities, Journal of Political Economy, 81, 637 - 654.

Chang, J. and Liao, S., 2010. Warrant introduction effects on stock return processes, Applied Financial Economics, 20, 17, 1377-1395.

Crouhy, M. and Galai, D., 1991. Common errors in the valuation of warrants and options on firms with warrants, Financial Analysts Journal, 47, 89 - 90.

Crouhy, M. and Galai, D., 1994. The interaction between the financial and investment decisions of the firm: The case of issuing warrants in a levered firm, Journal of Banking and Finance, 18, 861 - 880.

Darsinos, T. and Satchell, S.E., 2002. On the Valuation of Warrants and Executive Stock Options: Pricing Formulae for Firms with Multiple Warrants/Executive Options, Cambridge Working Papers in Economics 0218, Faculty of Economics, University of Cambridge.

Galai, D., 1989. A note on "Equilibrium warrant pricing models and accounting for executive stock options", Journal of Accounting Research, 27, 313 - 315.

Galai, D. and Schneller, M. I., 1978. Pricing of warrants and the value of the firm, Journal of Finance, 33, 1333 - 1342.

Handley, J. C., 2002. On the valuation of warrants, The Journal of Futures Markets, 22, 8, 765-782.

Ingersoll, J., 1987. Theory of Financial Decision Making, Rowman \& Littlefield, Savage.

Koziol, C., 2006. Optimal exercise strategies for corporate warrants, Quantitative Finance, 6, 1, 37 - 54 . 
Lauterbach, B. and Schultz, P., 1990. Pricing warrants: An empirical study of the Black-Scholes model and its alternatives, Journal of Finance, 45, 4, 1181 $-1209$.

Merton, R., 1973. Theory of rational option pricing, Bell Journal of Economics and Management Science, 4, 1, 141 - 183.

Modigliani, F. and Miller, M. H., 1958. The cost of capital, corporation finance and the theory of investments, American Economic Review, 48, 261-297.

Noreen, E. and Wolfson, M., 1981. Equilibrium warrant pricing models and accounting for executive stock options, Journal of Accounting Research, 19, 384 -398 .

Schulz, G.U. and Trautmann, S., 1994. Robustness of option-like warrant valuation, Journal of Banking and Finance, 18, 841 - 859.

Sidenius, J., 1996. Warrant pricing -Is dilution a delusion?, Financial Analysts Journal, 52, 5, 77-80.

Ukhov, A.D., 2004. Warrant pricing using observable variables, Journal of Financial Research, 27, 3, 329 - 339.

Veld, C., 2003. Warrant pricing: A review of empirical research, European Journal of Finance, 9, 61-91.

Yagi, K. and Sawaki K., 2010. The pricing and optimal strategies of callable warrants, European Journal of Operational Research, 206, 123-130. 


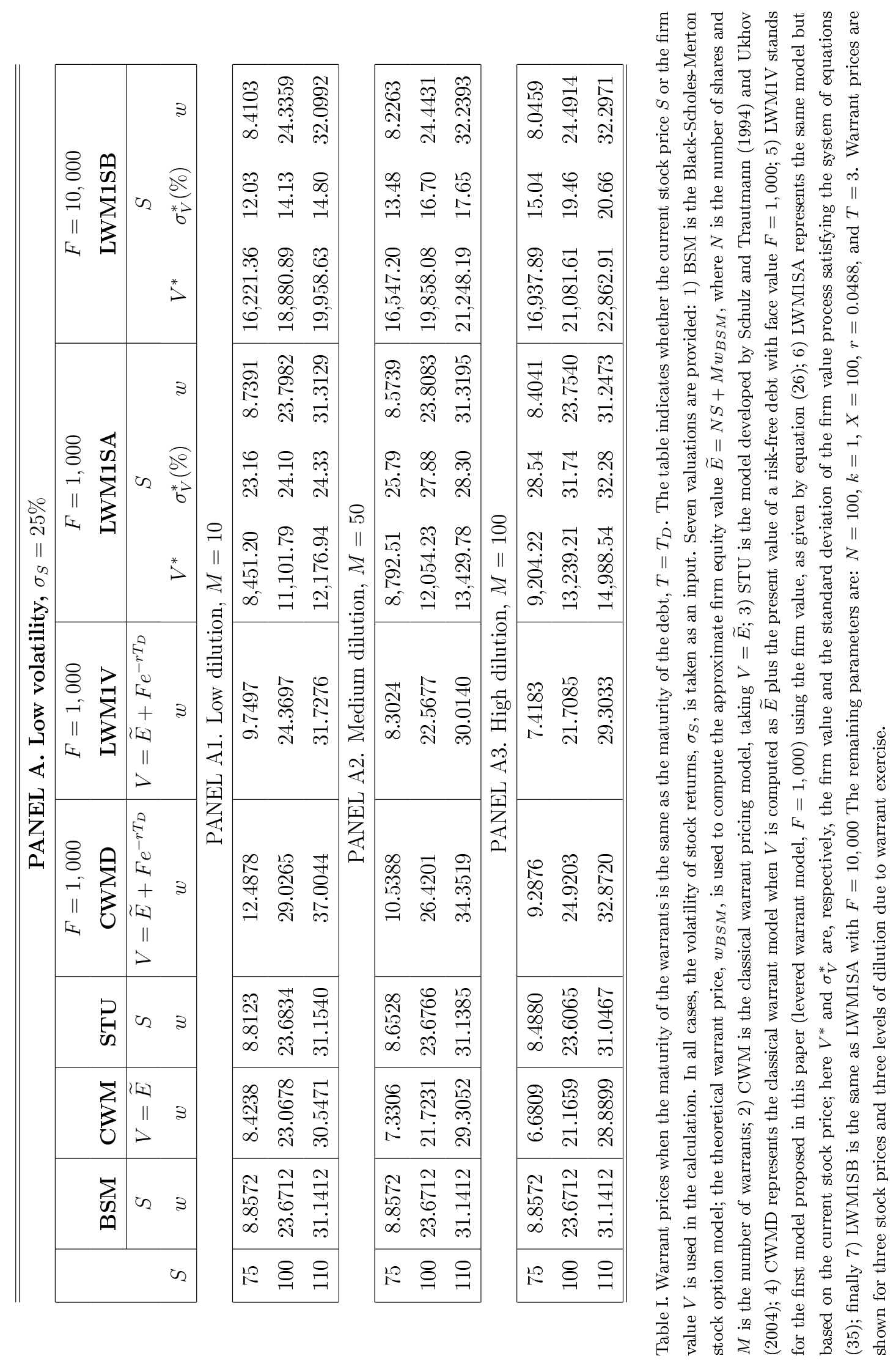




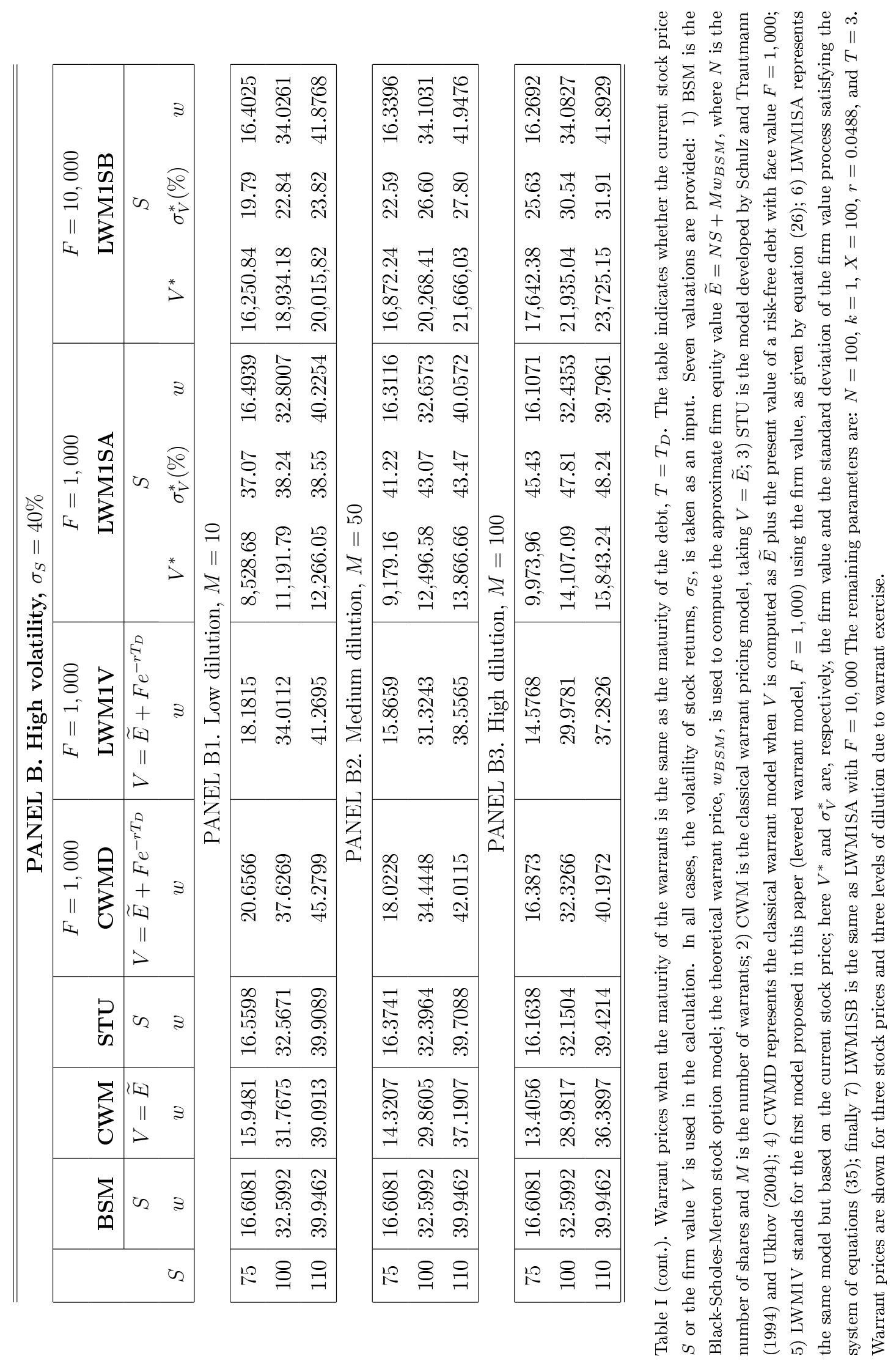




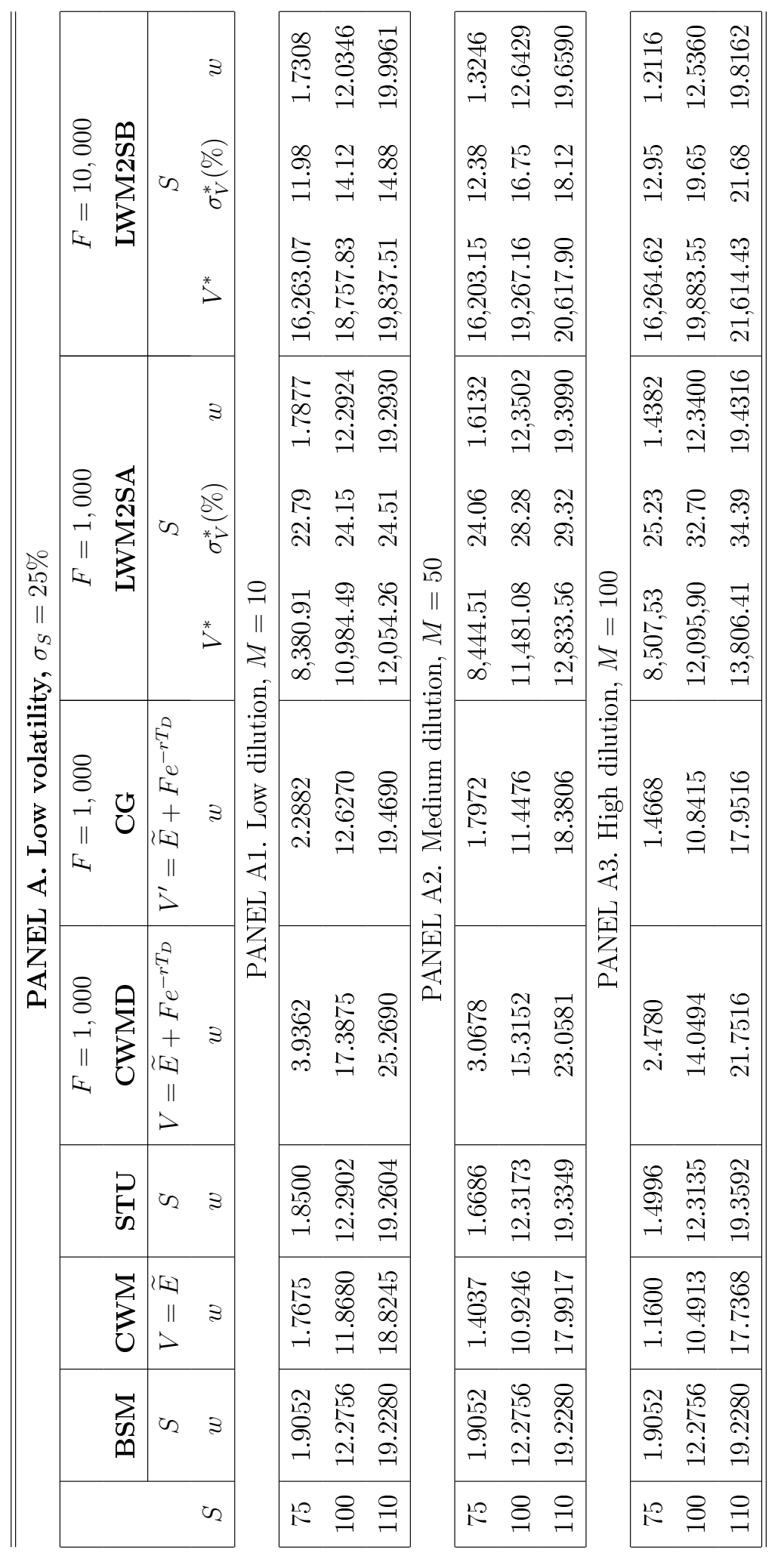

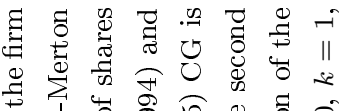
苛苟 边

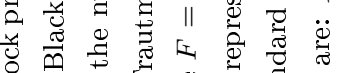
in

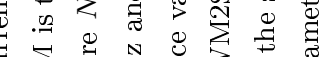

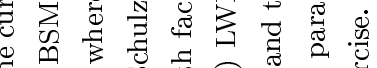

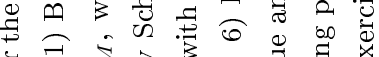

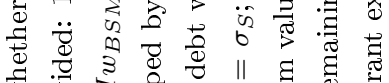

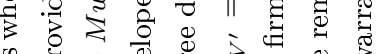
马ै

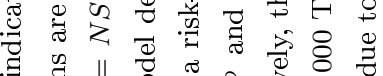
$\Rightarrow \|$ o $\pi .2$ 完莺任 可

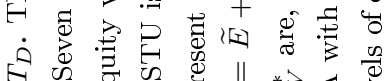
讨

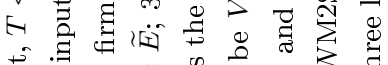

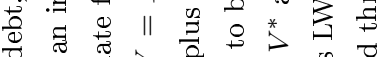

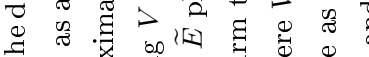

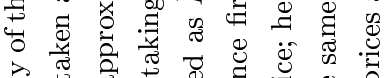
Ð ङ

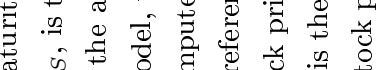

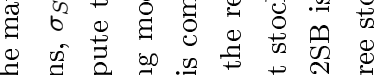
छ

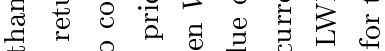

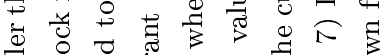
元 (2)

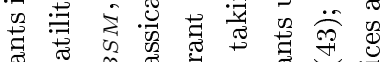

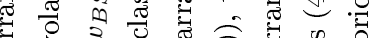

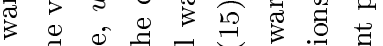

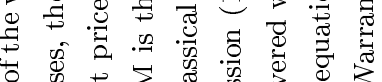

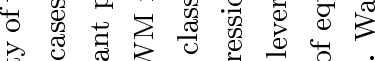

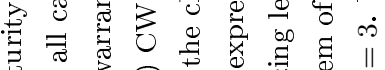

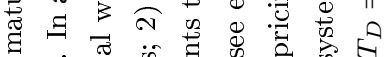

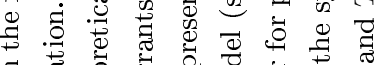

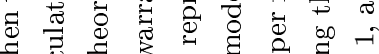
उँ ชू ฮु

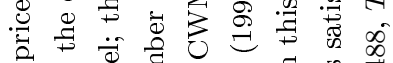

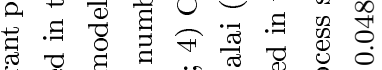

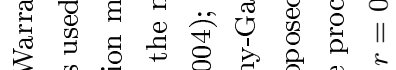

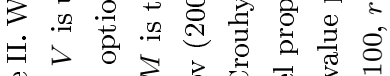

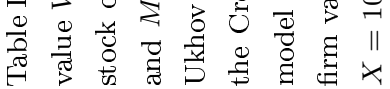




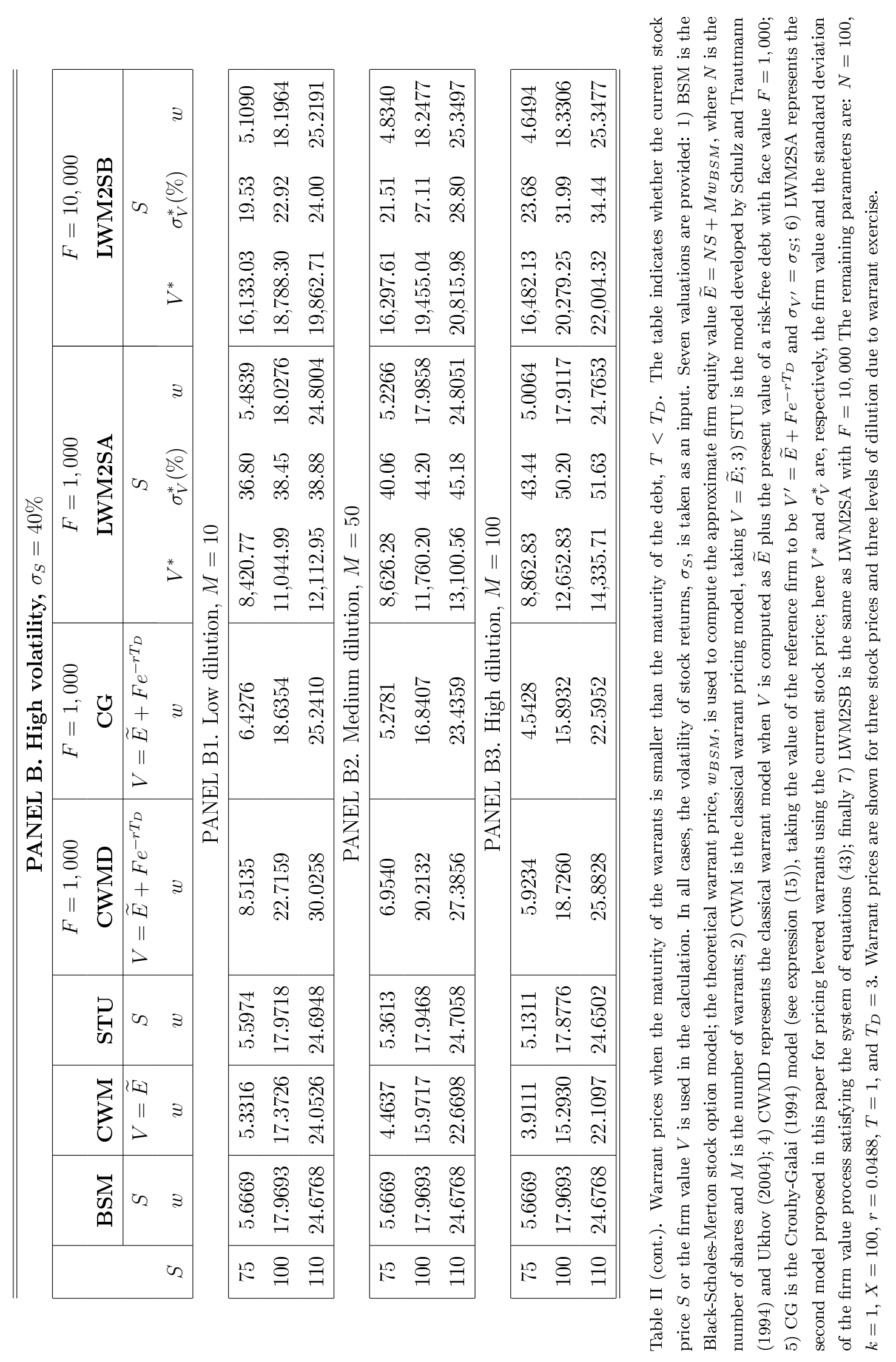




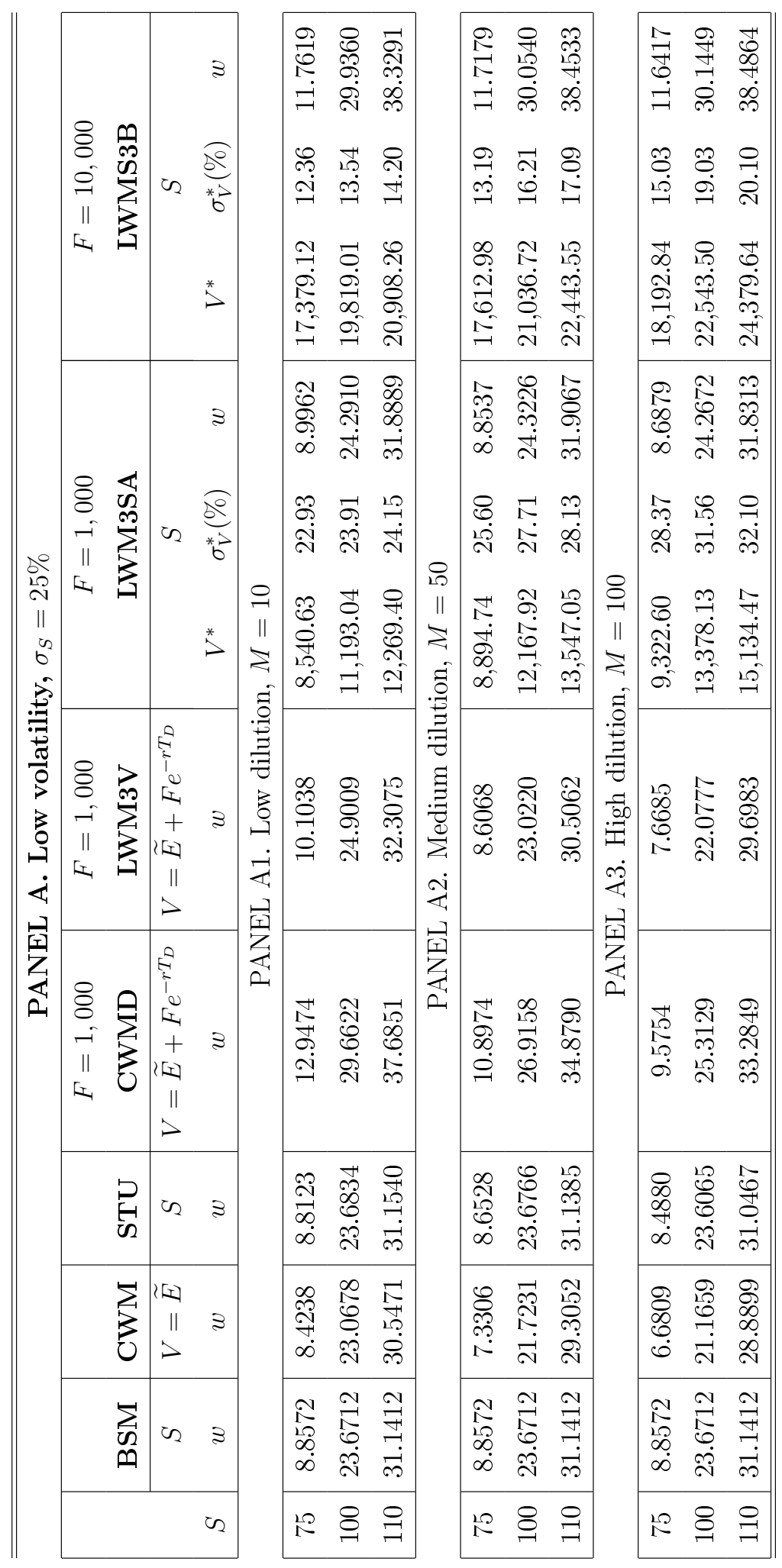

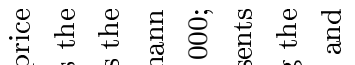

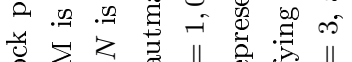

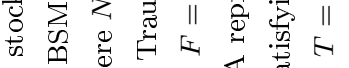

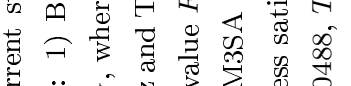

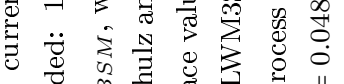

\&

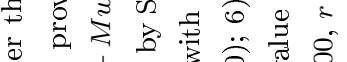

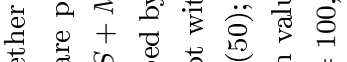

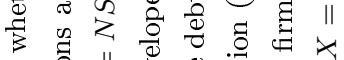

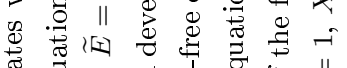

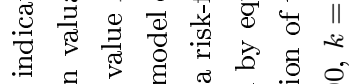

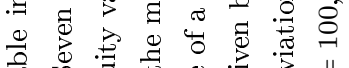

का

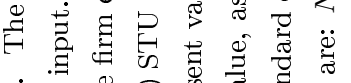

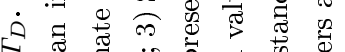

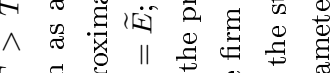

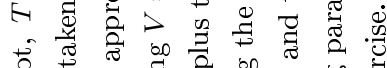

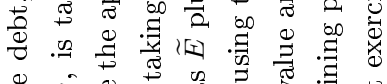

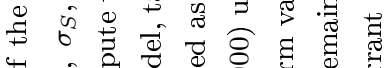

पे की

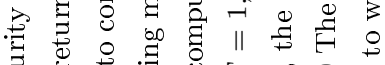

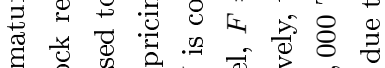

\%

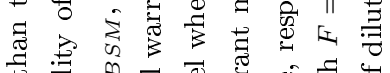

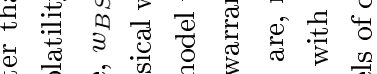

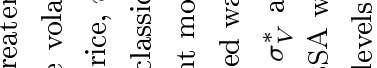

to

का

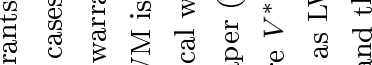

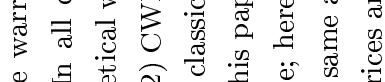

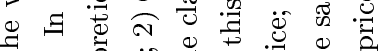

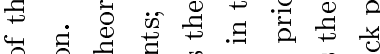

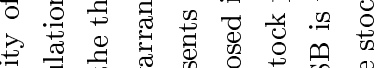

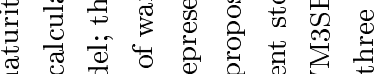

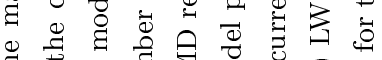

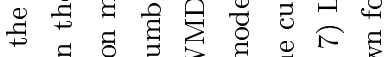

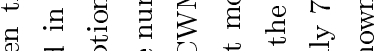

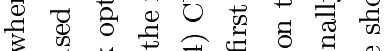

\&

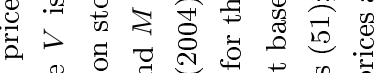

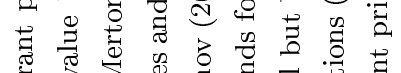

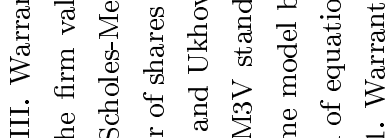

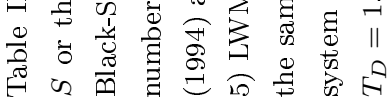




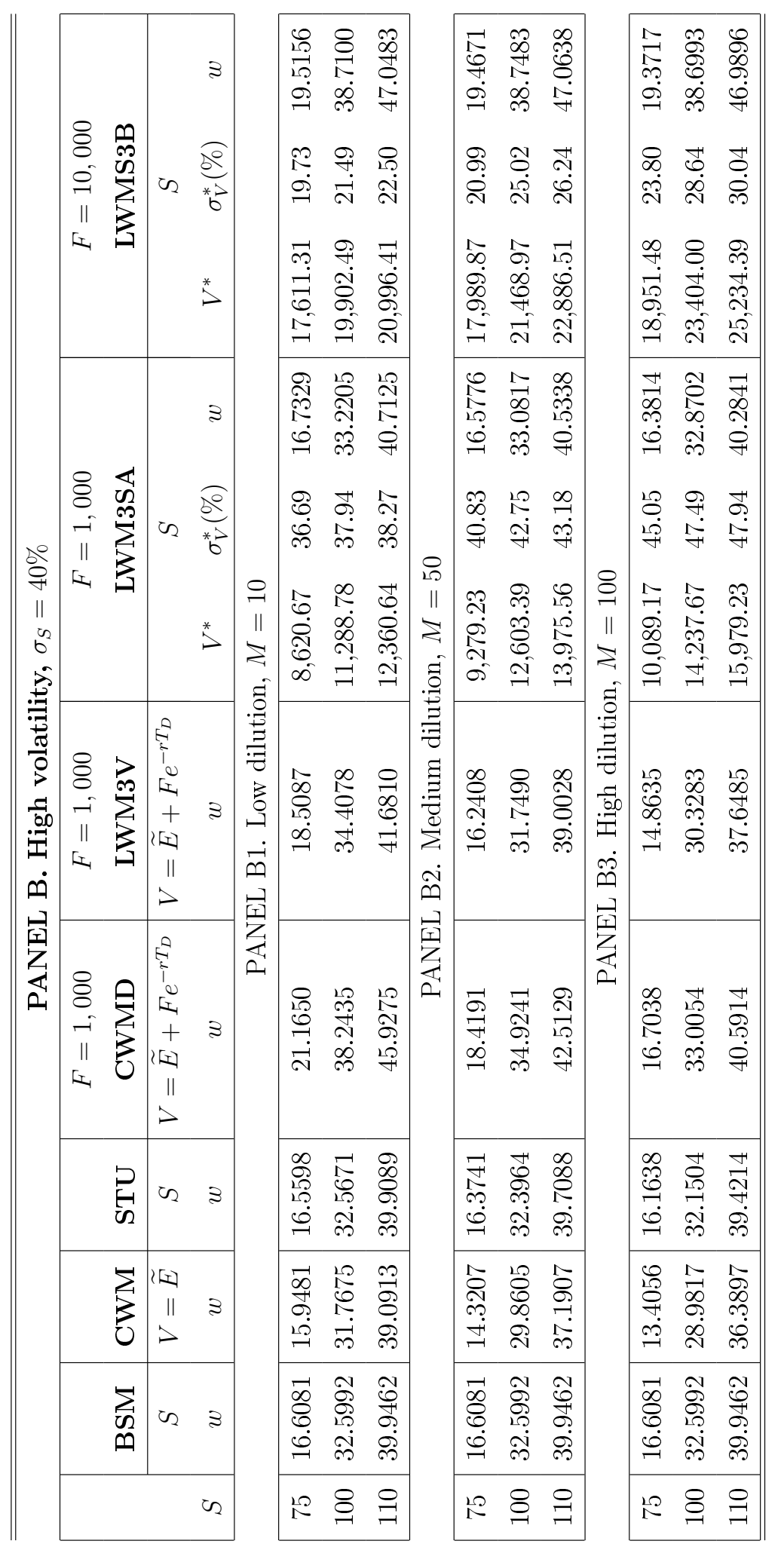

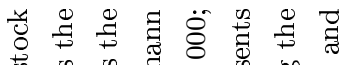

के .0 . है

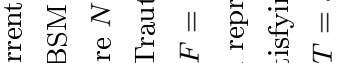

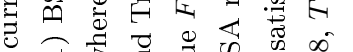

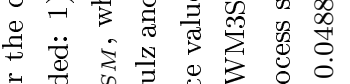

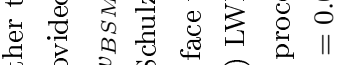

एक

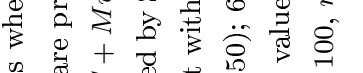

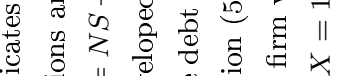

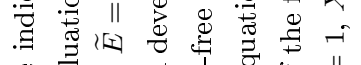

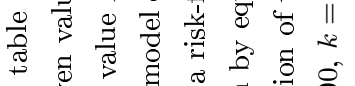

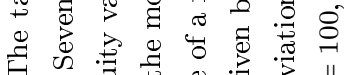

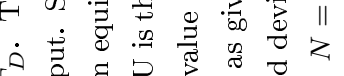

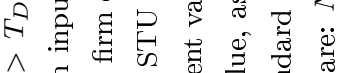
$\hat{A}$ สี

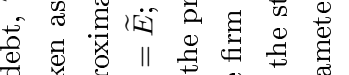

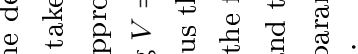

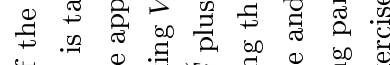

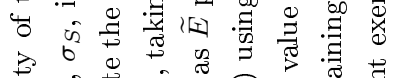

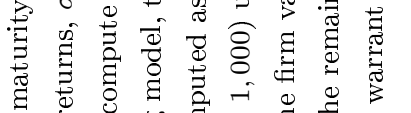
ऽ

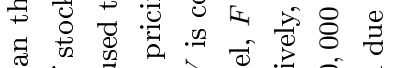
ఫี

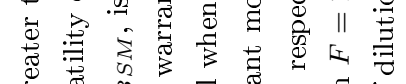

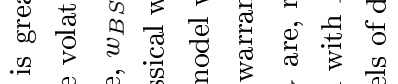

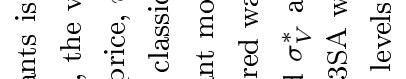

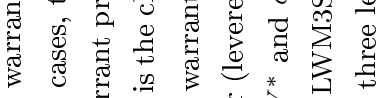

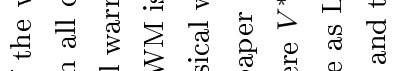

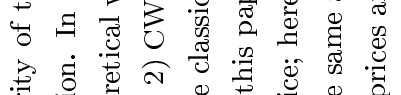
:

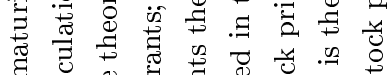

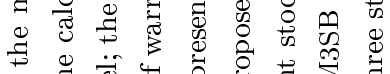

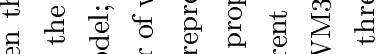
类 $\cong$ वे

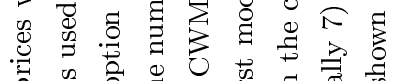

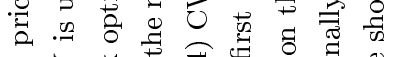
节入

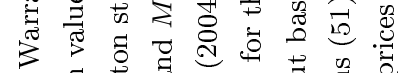

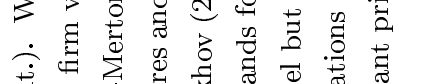

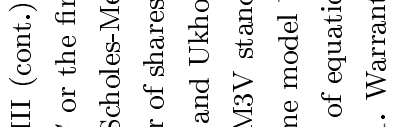

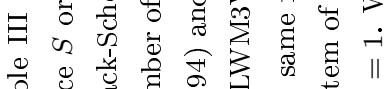

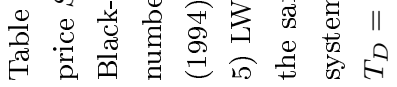

